Article

\title{
Highly Efficient Extracellular Production of Recombinant Streptomyces PMF Phospholipase D in Escherichia coli
}

\author{
Jing Wang ${ }^{\dagger}$, Sheng $\mathrm{Xu}^{\dagger}$, Yang Pang, Xin Wang *, Kequan Chen and Pingkai Ouyang \\ State Key Laboratory of Materials-Oriented Chemical Engineering, College of Biotechnology and \\ Pharmaceutical Engineering, Nanjing Tech University, Nanjing 211816, China; njtechwj@163.com (J.W.); \\ henryxu@njtech.edu.cn (S.X.); njtechpy@163.com (Y.P.); kqchen@njtech.edu.cn (K.C.); \\ ouyangpk@njtech.edu.cn (P.O.) \\ * Correspondence: xinwang1988@njtech.edu.cn \\ + These authors contributed equally to this work.
}

Received: 18 August 2020; Accepted: 11 September 2020; Published: 14 September 2020

\begin{abstract}
To achieve efficient bio-production of phospholipase D (PLD), PLDs from different organisms were expressed in E. coli. An efficient secretory expression system was thereby developed for PLD. First, PLDs from Streptomyces PMF and Streptomyces racemochromogenes were separately over-expressed in E. coli to compare their transphosphatidylation activity based on the synthesis of phosphatidylserine (PS), and PLD $\mathrm{PMF}_{\mathrm{F}}$ was determined to have higher activity. To further improve PLD $\mathrm{PMF}_{\text {synthesis, }}$ a secretory expression system suitable for PLD ${ }_{\text {PMF }}$ was constructed and optimized with different signal peptides. The highest secretory efficiency was observed when the PLD * (PLD PMF with the native signal peptide Nat removed) was expressed fused with the fusion signal peptide PelB-Nat in E. coli. The fermentation conditions were also investigated to increase the production of recombinant PLD and 10.5 U/mL PLD was ultimately obtained under the optimized conditions. For the application of recombinant PLD to PS synthesis, the PLD properties were characterized and $30.2 \mathrm{~g} / \mathrm{L}$ of PS was produced after $24 \mathrm{~h}$ of bioconversion when $50 \mathrm{~g} / \mathrm{L}$ phosphatidylcholine (PC) was added.
\end{abstract}

Keywords: phospholipase D; phosphatidylserine; secretory expression; enzymatic catalysis

\section{Introduction}

Phospholipase D (PLD, EC 3.1.4.4) catalyzes hydrolysis of the phosphodiester bond of glycerophospholipids to generate phosphatidic acid and a free head-group. In addition to its hydrolytic activity, PLD can also catalyze the transfer of acyl groups to directly synthesize valuable phospholipid derivatives, such as phosphatidylethanolamine (PE), phosphatidylserine (PS) and phosphatidylglycerol (PG) [1]. These phospholipids have wide applications in the food, cosmetics and pharmaceutical industries [2]. PLD was first reported in 1947 and due to its special catalytic activity, research on PLD has recently increased [3]. PLD has been identified from plants [4], mammals [5] and bacteria [6]. However, these natural sources produce low levels of PLD that cannot meet the industrial demand [7]. Therefore, the production of PLD by microbial fermentation has attracted great attention due to its advantages of high unit activity and low cost.

PLD has been characterized in many microorganisms and is most commonly found in Streptomyces strains, such as Streptomyces PMF [8], S. lividans [9], S. racemochromogenes [10] and Streptomyces sp. YU100 [11]. Compared with PLD from Streptomyces, PLD coming from other organisms has the transphosphatidylation activity, the activity is much lower [12]. For the production of PLD which has great potential in the industrial synthesis of high-value-added phospholipids, Streptomyces strains are most widely used due to the high transphosphatidylation activity of native PLD. For example, 
Saovanee et al. isolated Streptomyces sp. SC734 from soil-contaminated palm oil, and the PLD it produced exhibited high activity with a conversion rate of phosphatidylcholine (PC) to PS of up to $94.7 \%$ in $100 \mathrm{~min}$ [13]. Ogino et al. constructed an overexpression system for secretory production of PLD in S. lividans and the amount of PLD secreted reached a maximum level of $118 \mathrm{mg} / \mathrm{L}$ [14]. However, the genetic transfer systems for Streptomyces remain largely inefficient, which limits efficient production of PLD. Thus, the heterologous expression of Streptomyces PLDs in other model microorganisms, such as yeast or E. coli is highly desired.

Using Pichia pastoris as the host, Liu et al. developed a yeast cell surface display system to express PLD from S. chromofuscus, and the displayed PLD converted $67.5 \%$ of PC to PS within $10 \mathrm{~h}$ [15]. PLDs from different sources have also been successfully expressed in E. coli. For example, Zambonelli et al. expressed the PLD from Streptomyces PMF in E. coli BL21(DE3)pLysS, and $5 \mathrm{mg} / \mathrm{L}$ PLD was finally obtained with an enzyme activity of $15 \mathrm{mU} / \mathrm{mL}$ [16]. For the high-level and stable production of PLD, several engineering strategies were carried out in E. coli, including optimizing and tightly regulating promoter strength, optimizing codon usage and amino acid supplementation, and maintaining the best cellular state by supplementing nutrition. Finally, a large amount of PLD $(81.5 \mathrm{mg} / \mathrm{L})$ was obtained in batch culture [17]. Although there has been considerable progress in heterologous production of PLD, it is still not enough for industrial applications of PLD. Developing an efficient expression system for PLD production is urgently needed.

One of the biggest obstacles to efficient PLD production is that overexpressed PLD is toxic to the host, which may cause plasmid instability, cell lysis and PLD leakage [17]. Secretory production of heterologous proteins has great advantages compared with conventional cytosolic protein production, especially when the heterologous proteins are toxic. In addition, the secretory production of heterologous proteins could simplify the purification processes and reduce cost since cell disruption is not required. Many reports have proposed strategies for improving the secretory production of heterologous proteins, such as co-expression of the signal peptide [18], optimizing the environmental conditions [19], constructing leaky strains [20] or co-expressing the secretory pathway [21]. The production of PLD in the secretory form seems to be a promising approach to address this issue.

In this study, PLDs from Streptomyces PMF and Streptomyces racemochromogenes were separately overexpressed in E. coli to compare their transphosphatidylation activity based on synthesis of PS. Recombinant $P_{L D} D_{P M F}$ exhibited higher activity. To further improve the synthesis of $P_{L D} D_{P M F}$, a secretory expression system suitable for PLD ${ }_{\mathrm{PMF}}$ was constructed and optimized with different signal peptides. The highest secretory efficiency was observed when the PLD * was expressed fused with the fusion signal peptide Nat-PelB. After optimizing induction conditions including induction temperature, induction $\mathrm{pH}$, IPTG concentration, induction time and addition of metal ions, $10.5 \mathrm{U} / \mathrm{mL}$ PLD was detected in the fermentation medium. For the application of recombinant PLD to PS synthesis, the PLD properties were characterized and $30.2 \mathrm{~g} / \mathrm{L}$ of PS was produced after bioconversion for $24 \mathrm{~h}$ when $50 \mathrm{~g} / \mathrm{L}$ PC was added.

\section{Results}

\subsection{Intracellular Expression of PLD in E. coli}

The host strain E. coli BL21(DE3) is an efficient expression system for various recombinant proteins. Here we attempted to use it for the production of PLD. Two PLDs in the plasmids pET28a-PLD ${ }_{\text {PMF }}$ and pET28a-PLD $D_{S R}$ were separately introduced into BL21(DE3). Enzyme production was induced by the addition of IPTG and the activities of crude PLD extracts were compared. As shown in Figure 1, both PLDs were functionally expressed in E. coli, and crude extracts of the strain BL21(DE3)/pET28a-PLD ${ }_{\text {PMF }}$ exhibited higher transphosphatidylation activity. Using the intracellular fraction of the strain BL21(DE3)/pET28a-PLD ${ }_{\text {PMF }}$ for the bioconversion of PC to PS, PS reached $0.37 \mathrm{~g} / \mathrm{L}$ after $8 \mathrm{~h}$, which is 1.4-fold higher than that of BL21(DE3)/pET28a-PLD ${ }_{\mathrm{SR}}$. Besides this, we also tested 
the catalytic activity of the extracellular fraction of these two strains. Unfortunately, there was no PS detected. This result suggested that, almost all heterologous produced PLD was in the cell and the signal peptide from Streptomyces could not guide the secretion of PLD when it was expressed in E. coli. Relatively speaking, PLD PMF may be more suitable for expression in E. coli, although this may be a comprehensive result caused by factors such as intrinsic enzyme catalytic activity and enzyme production. Therefore, PLD PMF was applied to further optimize expression.

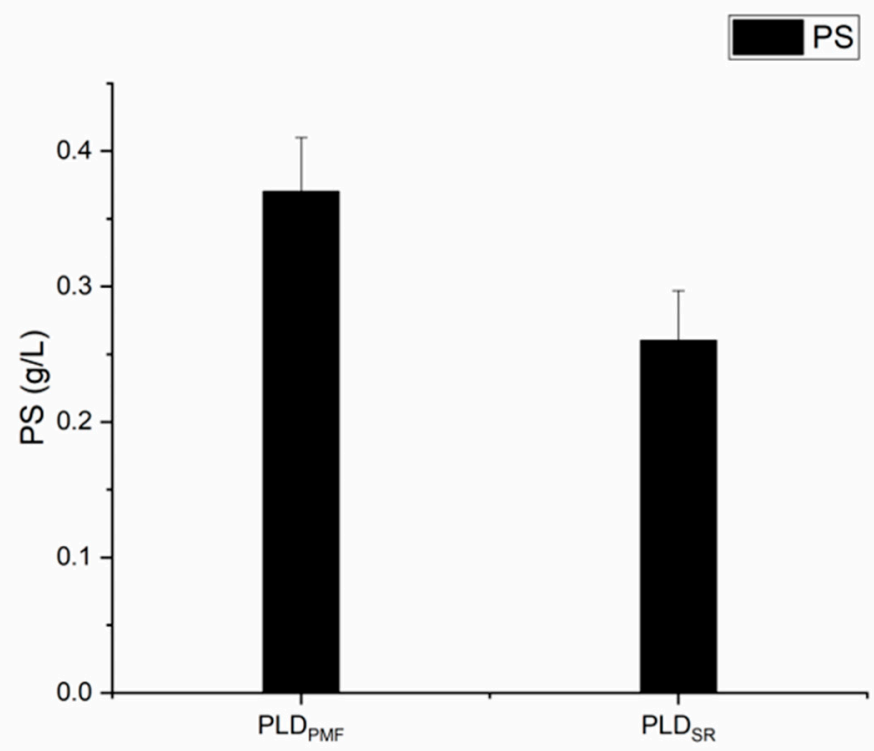

Figure 1. Comparison of the transphosphatidylation activity of the phospholipase D (PLD) coming from Streptomyces PMF and S. racemochromogenes when expressed in E. coli.

\subsection{Secretory Expression of PLD in E. coli by Optimizing Signal Peptides}

To investigate the secretory expression of PLD, the signal peptides Nat (Native signal peptide from PLD $\left.{ }_{\mathrm{PMF}}\right)$, OmpA and the fusion signal peptide OmpA-Nat were fused-expressed with the PLD * (Figure 2a). First, the effect of Nat and OmpA on the PLD secretory efficiency was compared. No PS was detected using the extracellular fraction of the strain BL21(DE3)/pET22b-Nat-PLD * for the conversion of PC to PS (Figure $2 b$ ), this result proved that signal peptide Nat could not guide the secretion of PLD when it was expressed in E. coli again. In contrast, the PS yield reached $40.68 \%$ after bioconversion for $24 \mathrm{~h}$ using the extracellular fraction of the strain BL21(DE3)/pET22b-OmpA-PLD *, indicating that OmpA is functional for directing the secretion of heterologous PLD in E. coli. Subsequently, to identify whether the cleavage of Nat sequence in the N-terminus of PLD PMF affected PLD activity, PLD * was expressed after being fused with OmpA-Nat in E. coli. Compared with PLD produced by BL21 (DE3)/pET22b-OmpA-PLD*, We found that the PLD from the strain BL21(DE3)/pET22b-OmpA-Nat-PLD * exhibited higher transphosphatidylation activity with PS yield of $45.72 \%$ after bioconversion for $24 \mathrm{~h}$. This result indicated that the Nat signal peptide may be important for maintaining the transphosphatidylation activity of recombinant PLD. Thus, the fused signal peptide was more suitable for the secretory expression of PLD in E. coli. 
(a)
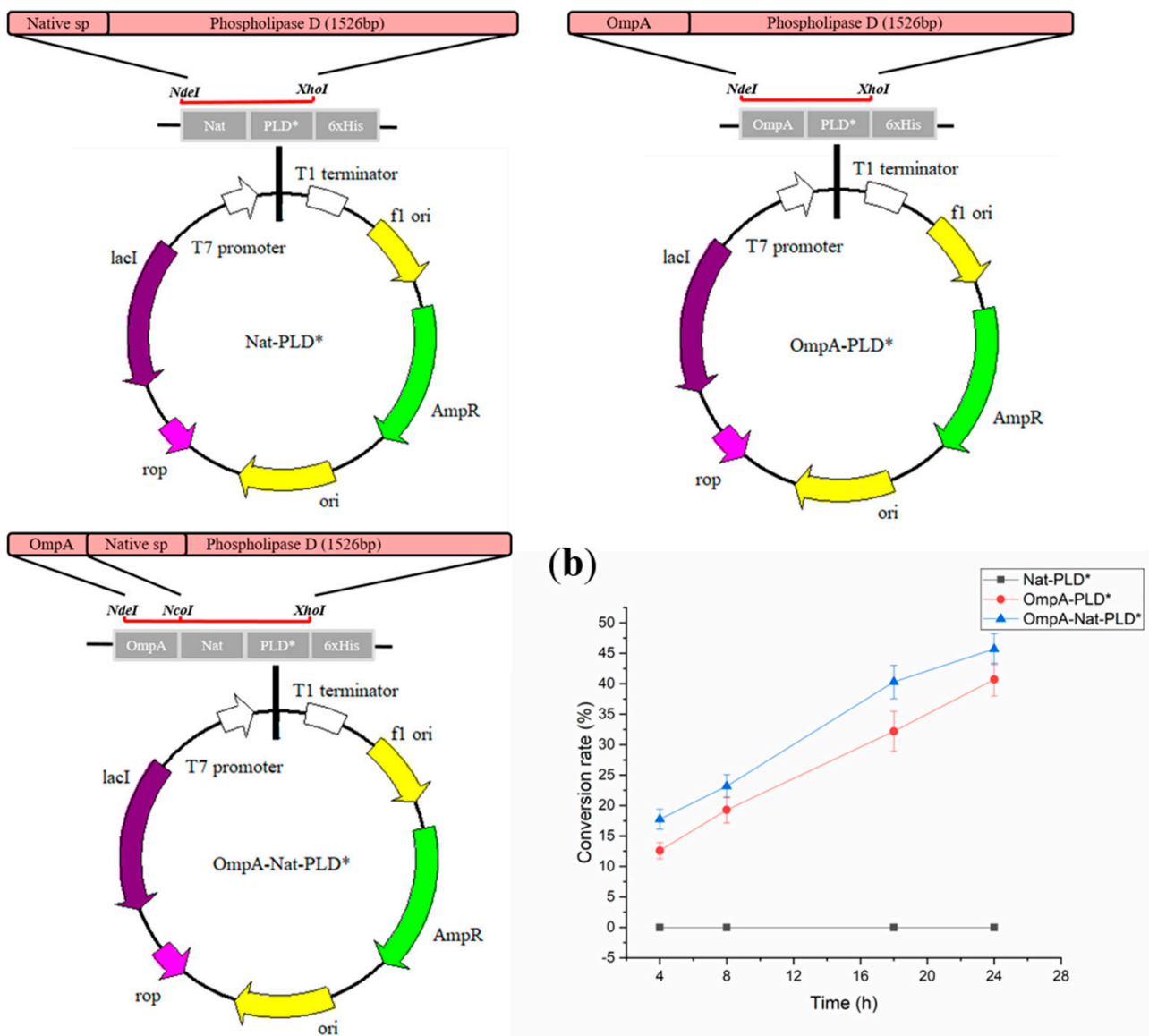

Figure 2. Effects of the Nat signal peptide on the transphosphatidyltion activity of recombinant PLD ${ }_{\text {PMF }}$ expressed by E. coli. (a) Structure of the plasmids Nat-PLD *, OmpA-PLD * and OmpA-Nat-PLD * (b) The conversion rates of phosphatidylcholine (PC) to phosphatidylserine (PS) catalyzed by the extracellular PLD expressed by the strain: BL21(DE3)/Nat-PLD *, BL21(DE3)/OmpA-PLD * and BL21(DE3)/OmpA-Nat-PLD *

To further determine the optimum signal peptide for directing secretion expression of PLD in E. coli, seven different signal peptides were employed to replace OmpA to form new fusion signal peptides. (Figure 3a). As shown in Figure 3b, different signal peptides directed export of PLD with varying efficiencies. Compared with OmpA-Nat, the fused signal peptides OmpF-Nat, OmpT-Nat, LamB-Nat and MalE-Nat are less efficient and lower PS yield was observed. In contrast, more efficient PLD secretion was obtained with the signal peptides OmpC-Nat, PhoA-Nat and PelB-Nat resulting in higher PS yield. Among them, the highest level of extracellular PLD * was found after expressing the plasmid PelB-Nat-PLD * in E. coli, where PS yield was increased by $86.51 \%$ compared to that from OmpA-Nat. Thus, the recombinant strain BL21(DE3)/pET22b-PelB-Nat-PLD * with the highest PLD secretory expression activity was selected for the following experiment. 
(a)

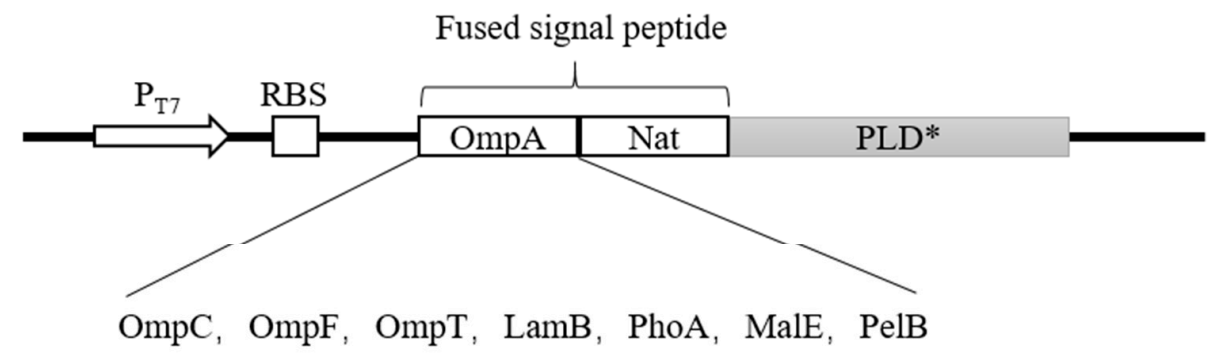

(b)

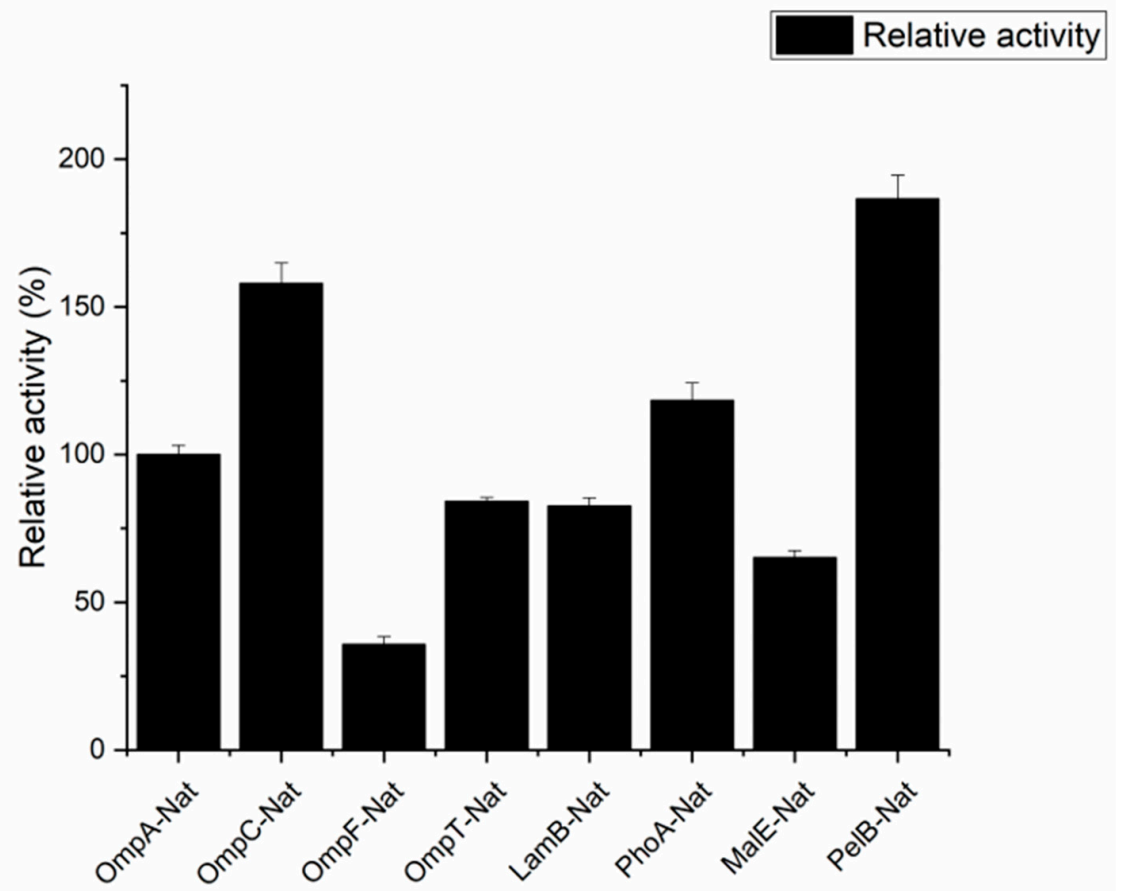

Figure 3. Optimization of the signal peptides for the secretory expression of PLD * in E. coli. (a) Using different signal peptides from E. coli to replace OmpA to construct different fused signal peptides. (b) The relative transphosphatidylation activity of recombinant PLD * when fused expressed in E. coli with different fusion signal peptides. The activity of PLD expressed by the strain BL21(DE3)/pET22b-OmpA-Nat-PLD * was the reference (100\% relative activity).

\subsection{Effect of Fermentation Conditions on the Secretory Expression of PLD}

To further improve PLD synthesis, fermentation conditions, including induction temperature, induction $\mathrm{pH}$, cell density at induction and IPTG concentration were optimized. For the control group, the induction temperature was $28^{\circ} \mathrm{C}$, IPTG concentration was $0.5 \mathrm{~mm}$, original cultivation $\mathrm{pH}$ was 7.0 , no surfactant was added, induction time was $12 \mathrm{~h}$ and the induction $\mathrm{OD}_{600 \mathrm{~nm}}$ was 0.6 . Compared with the control group, each group of experiments has only one single variable. Induction temperature is an important factor influencing heterologous protein expression in E. coli. The recombinant strain was incubated at a temperature ranging from $16{ }^{\circ} \mathrm{C}$ to $36^{\circ} \mathrm{C}$, and the maximum PLD activity was obtained at $20^{\circ} \mathrm{C}$ with an increase of $19.4 \%$ compared to the control group (Figure $4 \mathrm{a}$ ). The effect of the concentration of IPTG was evaluated by varying the concentration from $0.4 \mathrm{~mm}$ to $0.8 \mathrm{~mm}$. The highest PLD activity was achieved when $0.7 \mathrm{~mm}$ IPTG was added, which resulted in a $68.2 \%$ increase in PS yield (Figure $4 \mathrm{~b}$ ). The optimal induction $\mathrm{OD}_{600 \mathrm{~nm}}$ and time were also determined at the induction 
$\mathrm{OD}_{600}$ of 1.4 after induction for $12 \mathrm{~h}$ (Figure $4 \mathrm{c}, \mathrm{d}$ ). Varying $\mathrm{pH}$ of the growth environment change bacterial metabolic pathways, which might negatively affect the expression of heterologous protein in E. coli. In addition, $\mathrm{pH}$ also affects the charge state on the cell surface, and thus the permeability of the cell membrane, which has an important impact on the exchange of substances and the secretion of recombinant proteins. When the engineered BL21(DE3)/pET22b-PelB-Nat-PLD * was cultivated at $\mathrm{pH}$ ranging from 5.0 to 8.0 , the most suitable original cultivation $\mathrm{pH}$ for the secretory expression of PLD was 6.5 (Figure 4e).
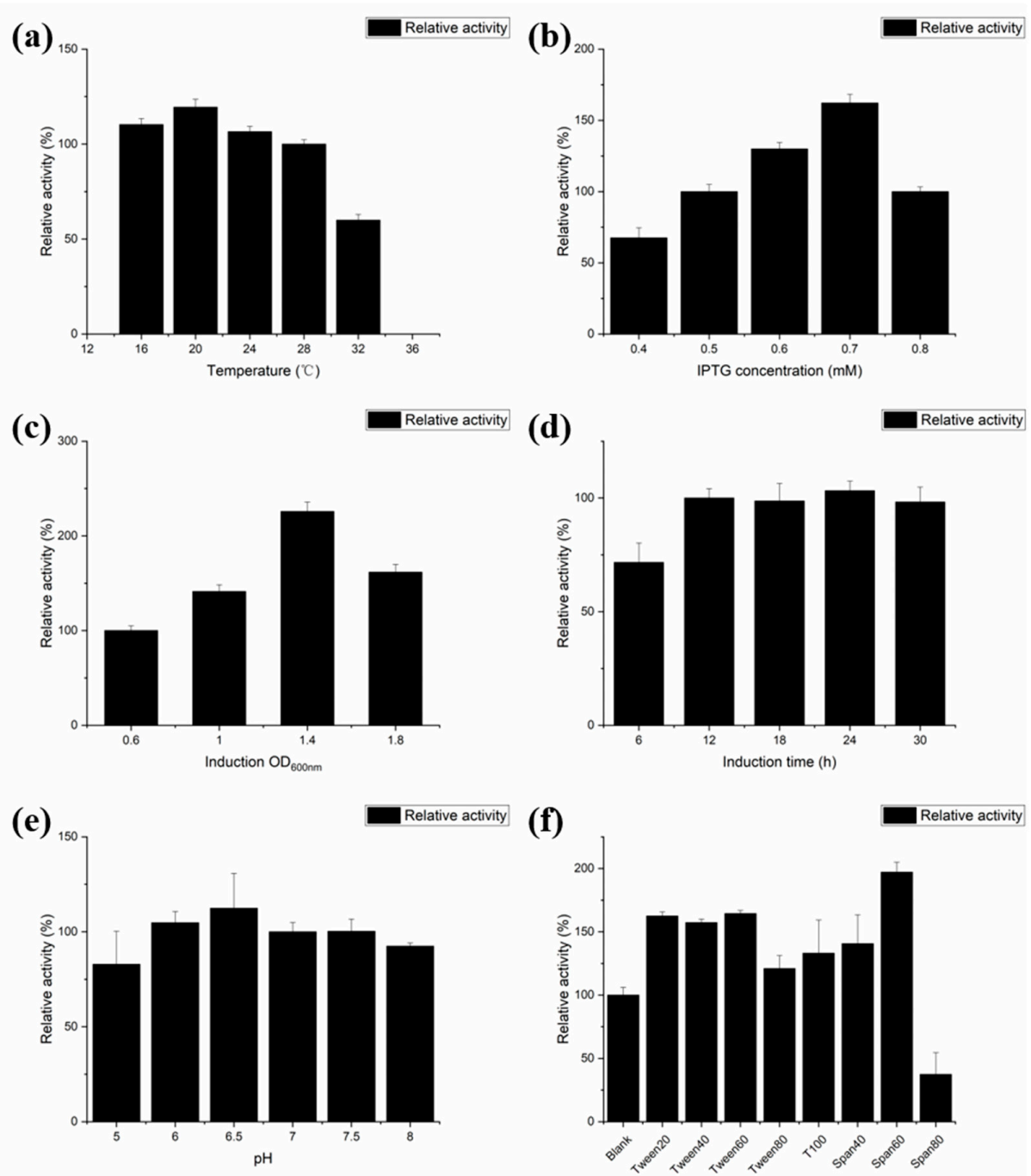

Figure 4. Optimization of the fermentation conditions for the secretory expression of PLDPMF. (a) The effect of induction temperature. (b) The effect of the concentration of $\beta$-d-1-thiogalactopyranoside (IPTG). (c) The effect of the induction $\mathrm{OD}_{600 \mathrm{~nm}}$. (d) The effect of the induction time. (e) The effect of the original cultivation $\mathrm{pH}$. (f) The effect of the addition of surfactants.

To further improve the secretory expression of recombinant PLD, the effects of surfactant addition were evaluated. As shown in Figure $4 \mathrm{f}$, seven different surfactants were separately added into the fermentation medium. Compared to the control group, all surfactants benefitted the secretory expression of PLD, among which, the group with $3 \mathrm{~g} / \mathrm{L}$ Span60 added exhibited the best PLD activity.

\subsection{Characterization of the Recombinant PLD Activity}

To characterize the recombinant PLD activity, the effects of reaction temperature, $\mathrm{pH}$ and metal ion additives were evaluated. The initial reaction was carried out under the following conditions: 
$30{ }^{\circ} \mathrm{C}, \mathrm{pH} 5.5$, no metal ions addition, and the activity of PLD was used as the reference value $(100 \%$ relative activity). To determine the optimal reaction temperature, bioconversion was carried out at $20,25,30,35$ or $40^{\circ} \mathrm{C}$ (Figure 5a). From $20^{\circ} \mathrm{C}$ and $30^{\circ} \mathrm{C}$, the PLD activity clearly increased with increasing temperature, and reached the highest level at $30^{\circ} \mathrm{C}$. When the temperature was higher than $30^{\circ} \mathrm{C}$, the PLD activity sharply decreased, indicating the temperature sensitivity of recombinant PLD. The PLD activity increased with a rise in reaction $\mathrm{pH}$ (from 4.0 to 8.0 ) and reached a maximum at pH 5.5 (Figure 5b).
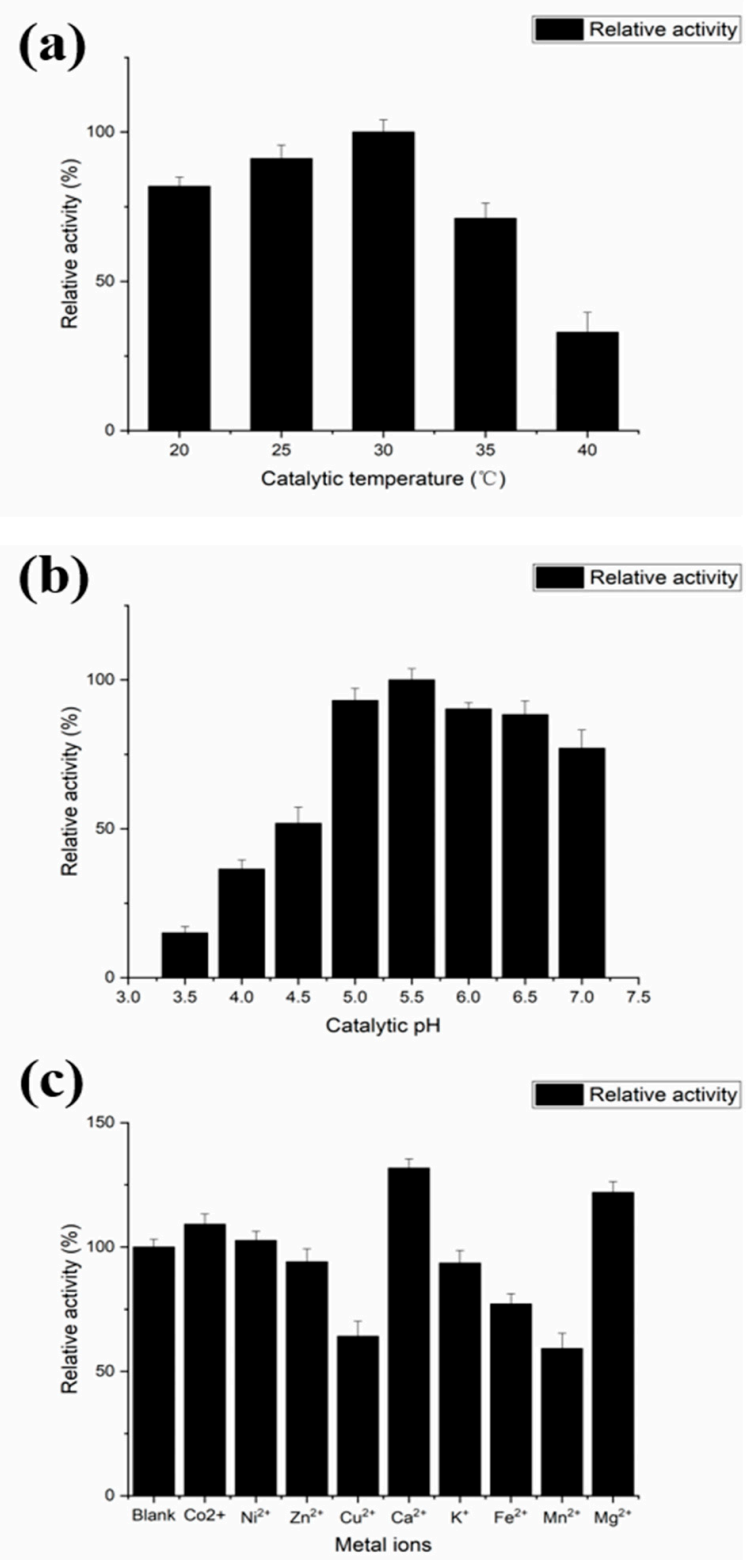

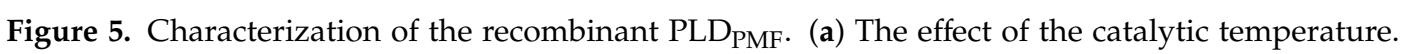
(b) The effect of the catalytic $\mathrm{pH}$. (c) The effect of the addition of metal ions.

Several metal ions have been reported to play an important role in maintaining the activity of PLD [22]. To evaluate the effect of metal ions on recombinant PLD activity, $10 \mathrm{~mm}$ metal ion $\left(\mathrm{Co}^{2+}\right.$, $\mathrm{Ni}^{2+}, \mathrm{Zn}^{2+}, \mathrm{Cu}^{2+}, \mathrm{Ca}^{2+}, \mathrm{K}^{+}, \mathrm{Fe}^{2+}, \mathrm{Mg}^{2+}, \mathrm{Mn}^{2+}$ ) was added into the aqueous phase. The reaction performed without any metal ions served as the control group. The addition of $\mathrm{Co}^{2+}, \mathrm{Ca}^{2+}$ and $\mathrm{Mg}^{2+}$ showed positive effects on the PLD activity, and the addition of $\mathrm{Ca}^{2+}$ gave the highest level of PLD activity (Figure 5c). 


\subsection{The Application of Recombinant PLD $P M F$ for the Bioconversion of PC to PS}

The optimum expression system (PelB-Nat fused-expressed with PLD *), fermentation conditions (induction temperature: $2{ }^{\circ} \mathrm{C}$; IPTG concentration: $0.7 \mathrm{~mm}$; induction $\mathrm{OD}_{600 \mathrm{~nm}}$ : 1.4 ; induction time: $12 \mathrm{~h}$; original fermentation $\mathrm{pH}$ : 6.5; addition of surfactant: $3 \mathrm{~g} / \mathrm{L}$ Span60) and PLD traits (catalytic temperature: $30^{\circ} \mathrm{C}$; original catalytic $\mathrm{pH}$ : 5.5 ; addition of metal ions: $10 \mathrm{~mm} \mathrm{Ca}^{2+}$ ) were determined based on the above results. With the extracellular recombinant PLD produced by engineered E. coli, the capacity of producing PS from PC by PLD was tested under the optimal reaction conditions. The reaction was performed with PC substrate concentrations of $10 \mathrm{~g} / \mathrm{L}, 30 \mathrm{~g} / \mathrm{L}$ and $50 \mathrm{~g} / \mathrm{L}$. Samples were taken at reaction times of $4 \mathrm{~h}, 8 \mathrm{~h}, 12 \mathrm{~h}$ and $24 \mathrm{~h}$ to detect the amount of product PS and substrate PC (Figure 6). In the case of $10 \mathrm{~g} / \mathrm{L} \mathrm{PC}$, after bioconversion of $24 \mathrm{~h}$, the production of PS reached $9.2 \mathrm{~g} / \mathrm{L}$ with a molar yield of $88.05 \%$. When the concentration of PC was increased to $30 \mathrm{~g} / \mathrm{L}$, the final PS titer of $18.2 \mathrm{~g} / \mathrm{L}$ was obtained with a molar yield of $58.02 \%$ after bioconversion of $24 \mathrm{~h}$. Further increasing PC concentration to $50 \mathrm{~g} / \mathrm{L}$, increased PS titer to $30.2 \mathrm{~g} / \mathrm{L}$ with a molar yield of $57.81 \%$.

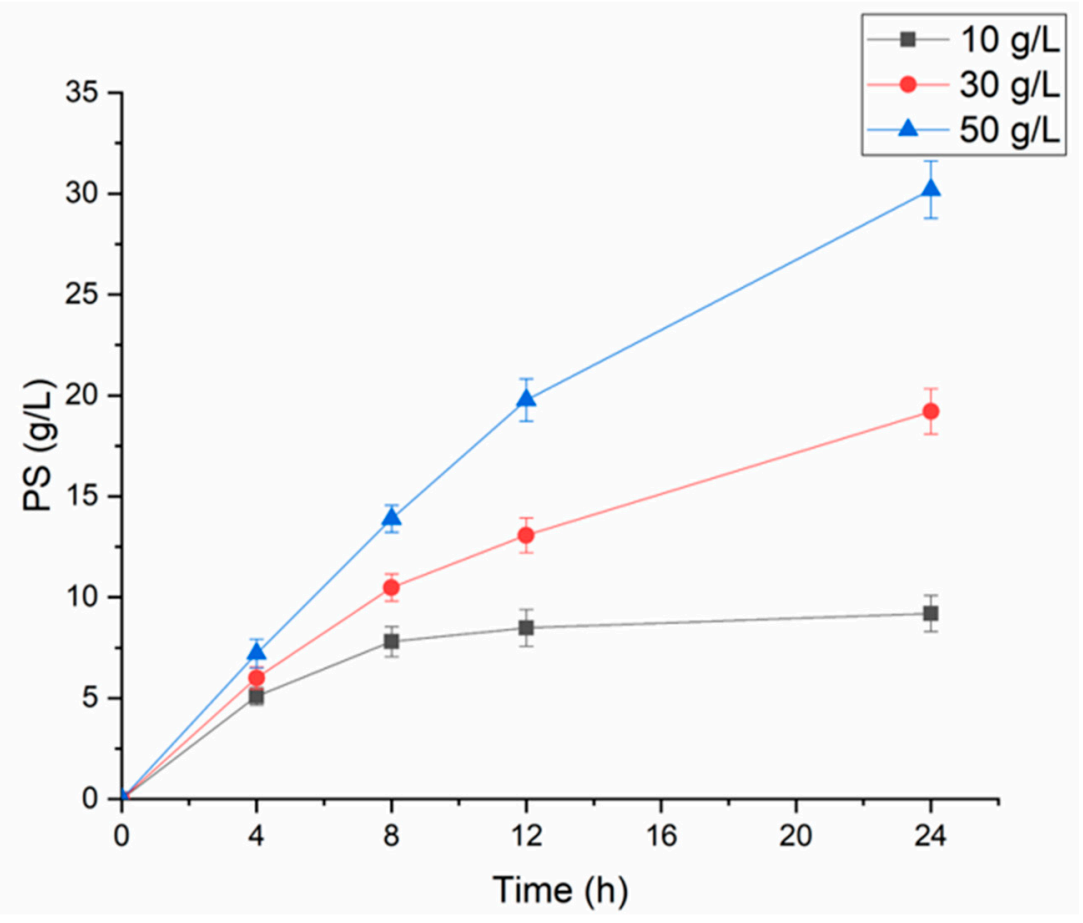

Figure 6. Using the recombinant $\mathrm{PLD}_{\mathrm{PMF}}$ for the bioconversion of PC to PS.

\section{Discussion}

Phospholipase has achieved significant attention in recent years for its applications in the production of various high value rare phospholipids [23]. To achieve high production of PLD, overexpression of native PLD or heterologous expression of various PLDs in model microorganisms, including E. coli [24], yeast [25] and Bacillus subtilis [26] have been performed. Among them, E. coli is the most frequently used host strain for the expression of heterologous proteins due to its well-characterized genetics, high protein expression levels and rapid growth rate [27]. However, the toxicity from overexpressing PLD has limited its production in E. coli. In this work, after screening PLD sources, a secretory PLD expression system was developed and optimized by investigating the effects of different signal peptides for efficient PLD production.

After determining a suitable source of PLD, OmpA, a signal peptide that has been reported to guide the secretory expression of heterologous proteins with high efficiency in E. coli [28], was first employed to direct the secretory production of recombinant PLD. The effect of native signal peptide (Nat) in PLD $_{\text {PMF }}$ sequence was also evaluated. Fortunately, the PLD production efficiency was largely enhanced 
with the secretory expression system. Moreover, the presence of Nat signal peptides resulted in a higher extracellular PLD activity, suggesting that the Nat sequence might contribute to the correct fold of recombinant PLD in E. coli. It is well known that the N-terminal signal sequence can guide the protein to the Sec-translocon through the post-translational SecB-targeting pathway or the co-translational signal recognition particle (SRP)-targeting pathway and then fold correctly [29]. However, there is currently no general rule in selecting a proper signal sequence for a given recombinant protein [30]. To identify a more efficient signal peptide to direct PLD secretion in E. coli, seven other signal peptides including OmpF-Nat, OmpT-Nat, OmpC-Nat, LamB-Nat, MalE-Nat, PhoA-Nat and PelB-Nat were compared. The highest secreted PLD activity occurred with PelB-Nat (Figure 3b), indicating the important role of signal peptide for the efficient production of recombinant PLD.

For the secretory production of recombinant proteins, membrane permeability might be a limiting factor since the cellular membrane often retards the entry of substrate into the cellular systems and prevents the product from being released from the cellular system for an easy recovery [31]. With the addition of $3 \mathrm{~g} / \mathrm{L}$ Span60, the extracellular PLD activity was increased by $97.1 \%$, indicating that cell membrane permeability is one of the key factors affecting secretory expression of recombinant PLD in E. coli. To address this issue, co-expression of the key secretion components, construction of leaky strains and utilization of different secretion pathways to enhance secretory production of heterologous PLD could be further carried out in future studies.

For applying PLD to the synthesis of high-value-added phospholipid, the properties of recombinant PLD were also characterized. As shown in Figure 5a, recombinant PLD is sensitive to temperature changes. The best $\mathrm{pH}$ for PLD activity was observed under $\mathrm{pH}$ 5.5, which coincides with other reports in which PLD exerted high transphosphatidylation activity in a weak acid environment [32]. For the metal ion additives, the highest PLD activity was observed with the addition of $\mathrm{Ca}^{2+}[12]$. $\mathrm{Ca}^{2+}$ binding to PLD has been reported to cause a conformational change in the PLD that enhances binding of protein to zwitterionic interfaces [13]. $\mathrm{Ca}^{2+}$ is also an activator when other soluble substrates are used [33]. $\mathrm{Ca}^{2+}$ possibly coordinates with enzymes, improving their stability. Finally, the recombinant PLD was applied for the bioconversion of PC to PS.

Previous reports on the enzymatic synthesis of PS focused on the use of PLDs expressed in Streptomyces. PS synthesis with a conversion rate of $88 \%$ was documented using the PLD from S. racemochromogenes [10]. Duan and Hu compared five commercial PLDs in the synthesis of PS, and PLD derived from S. chromofuscus achieved 90\% yield of PS after $12 \mathrm{~h}$ of bioconversion [34]. In our work, the recombinant PLD converted $88.05 \%$ of PC into PS with a concentration of $10 \mathrm{~g} / \mathrm{L} \mathrm{PC}$, indicating the high transphosphatidylation activity of the recombinant PLD expressed by E. coli. Under optimized conditions, $30.2 \mathrm{~g} / \mathrm{L}$ PS was obtained with a yield of $57.81 \%$. The recombinant PLDs obtained in E. coli are summarized in Table 1, and the highest PS concentration so far was obtained in our study.

Table 1. Production of recombinant PLD in E. coli and synthesis of PS.

\begin{tabular}{cccc}
\hline PLD Origin & Expression Host & PS (g/L) & References \\
\hline Streptomyces mobaraensis & E. coli & 0.2 & {$[12]$} \\
Streptomyces chromofuscus & E. coli & 3.94 & {$[35]$} \\
Streptomyces sp. YU100 & E. coli & ND & {$[11]$} \\
Streptomyces antibioticus & E. coli & ND & {$[17]$} \\
Streptomyces PMF & E. coli & 30.2 & This study \\
\hline
\end{tabular}

\section{Materials and Methods}

\subsection{Microorganisms and Media}

The strains used and constructed in this paper are listed in Table 2. The E. coli strains were cultured in Luria-Bertani medium (tryptone $10 \mathrm{~g} / \mathrm{L}, \mathrm{NaCl} 5 \mathrm{~g} / \mathrm{L}$ and yeast extract $5 \mathrm{~g} / \mathrm{L}$ ) containing appropriate antibiotics at the following concentrations: $50 \mathrm{mg} / \mathrm{L}$ kanamycin (kana) and $100 \mathrm{mg} / \mathrm{L}$ 
ampicillin (Amp). Plasmid pET28a was used as the original plasmid. L-serine, phosphatidylserine (PS) and phosphatidylcholine (PC) were purchased from Aladdin Ind. Co., Ltd. (China). $\mathrm{CoCl}_{2} \cdot 6 \mathrm{H}_{2} \mathrm{O}$, $\mathrm{KCl}, \mathrm{CaCl}_{2}, \mathrm{MgCl}_{2} \cdot 6 \mathrm{H}_{2} \mathrm{O}, \mathrm{FeCl}_{2}, \mathrm{MnCl}_{2} \cdot 4 \mathrm{H}_{2} \mathrm{O}, \mathrm{NiCl}_{2} \cdot 6 \mathrm{H}_{2} \mathrm{O}$ and $\mathrm{ZnCl}_{2}$ were purchased from Xilong Chemical Company (China).

Table 2. Strains and plasmids used in this study.

\begin{tabular}{|c|c|c|}
\hline Strains or Plasmids & Characteristics & Sources \\
\hline Strains & - & - \\
\hline Streptomyces PMF & Source of PLD PMF gene & ATCC \\
\hline Streptomyces racemochromogenes & Source of PLD $\mathrm{SR}$ gene & ATCC \\
\hline E. coli $\mathrm{DH} 5 \alpha$ & Used as cloning vector & Invitrogen \\
\hline E. coli BL21(DE3) & Used as expression host & Invitrogen \\
\hline BL21(DE3)/pET28a-PLD PMF & Express plasmid: pET28a-PLD ${ }_{\text {PMF }}$ & This study \\
\hline BL21(DE3)/pET28a-PLD & Express plasmid: pET28a-PLD ${ }_{S R}$ & This study \\
\hline BL21(DE3)/pET22b-PLD & Express plasmid: pET22b-PLD ${ }_{\mathrm{PMF}}$ & This study \\
\hline BL21(DE3)/Nat-PLD * & Express plasmid: Nat-PLD * & This study \\
\hline BL21(DE3)/OmpA-PLD * & Express plasmid: OmpA-PLD * & This study \\
\hline BL21(DE3)/OmpA-Nat-PLD * & Express plasmid: OmpA-Nat-PLD * & This study \\
\hline BL21(DE3)/OmpC-Nat-PLD * & Express plasmid: OmpC-Nat-PLD * & This study \\
\hline BL21(DE3)/OmpF-Nat-PLD * & Express plasmid: OmpF-Nat-PLD * & This study \\
\hline BL21(DE3)/OmpT-Nat-PLD * & Express plasmid: OmpT-Nat-PLD * & This study \\
\hline BL21(DE3)/LamB-Nat-PLD * & Express plasmid: LamB-Nat-PLD * & This study \\
\hline BL21(DE3)/PhoA-Nat-PLD * & Express plasmid: PhoA-Nat-PLD * & This study \\
\hline BL21(DE3)/MalE-Nat-PLD * & Express plasmid: MalE-Nat-PLD * & This study \\
\hline BL21(DE3)/PelB-Nat-PLD * & Express plasmid: PelB-Nat-PLD * & This study \\
\hline Plasmids & $1+-$ & - \\
\hline $\mathrm{pET} 28 \mathrm{a}$ & pBR322 ori, $\mathrm{P}_{\mathrm{T} 7}, \mathrm{Kan}^{\mathrm{R}}$ & Our lab \\
\hline pET22b & pBR322 ori, $P_{T 7}$, OmpA signal peptide, $\mathrm{Amp}^{\mathrm{R}}$ & Our lab \\
\hline pET28a-PLDPMF & pET28a derivative; $\mathrm{P}_{\mathrm{T} 7-\mathrm{lacO}} \mathrm{PLD}_{\mathrm{PMF}}$ & This study \\
\hline pET28a-PLD & pET28a derivative; $\mathrm{P}_{\mathrm{T} 7-\mathrm{lacO}}-\mathrm{PLD}_{\mathrm{SR}}$ & This study \\
\hline pET22b-PLD & pET22b derivative; $\mathrm{P}_{\mathrm{T} 7-\mathrm{lacO}}-\mathrm{OmpA-PLD} \mathrm{PMF}_{\mathrm{P}}$ & This study \\
\hline Nat-PLD* & pET22b derivative; $\mathrm{P}_{\mathrm{T} 7-\mathrm{lacO}}$-Nat-PLD * & This study \\
\hline OmpA-PLD * & pET22b derivative; $\mathrm{P}_{\mathrm{T} 7-\mathrm{lacO}}-\mathrm{OmpA-PLD}$ * & This study \\
\hline OmpA-Nat-PLD * & pET22b derivative; $\mathrm{P}_{\mathrm{T} 7-\mathrm{lacO}}-\mathrm{OmpA}-\mathrm{Nat}-\mathrm{PLD}$ * & This study \\
\hline OmpC-Nat-PLD * & pET22b derivative; $\mathrm{P}_{\mathrm{T} 7-\mathrm{lacO}}$-OmpC-Nat-PLD * & This study \\
\hline OmpF-Nat-PLD * & pET22b derivative; $\mathrm{P}_{\mathrm{T} 7-\mathrm{lacO}}-\mathrm{OmpF}-\mathrm{Nat}-\mathrm{PLD}$ * & This study \\
\hline OmpT-Nat-PLD * & pET22b derivative; $\mathrm{P}_{\mathrm{T} 7-\mathrm{lacO}}-\mathrm{OmpT}$-Nat-PLD * & This study \\
\hline LamB-Nat-PLD * & pET22b derivative; $\mathrm{P}_{\mathrm{T} 7-\mathrm{lacO}}$-LamB-Nat-PLD * & This study \\
\hline PhoA-Nat-PLD * & pET22b derivative; $\mathrm{P}_{\mathrm{T} 7-\mathrm{lacO}}$-PhoA-Nat-PLD * & This study \\
\hline MalE-Nat-PLD * & pET22b derivative; $\mathrm{P}_{\mathrm{T} 7-\mathrm{lacO}}$-MalE-Nat-PLD * & This study \\
\hline PelB-Nat-PLD * & pET22b derivative; $\mathrm{P}_{\mathrm{T} 7-\mathrm{lacO}}$-PelB-Nat-PLD * & This study \\
\hline
\end{tabular}

PLD *: the PLD ${ }_{\text {PMF }}$ with the native signal peptide (Nat) removed.

\subsection{Plasmid Construction}

All the primers used in this study are listed in Table 3. Two PLD gene fragments, PLDPMF and $\mathrm{PLD}_{\mathrm{SR}}$ were amplified from genomic DNA of Streptomyces PMF and Streptomyces racemochromogenes, respectively. The signal peptide genes OmpC, OmpF, OmpT, LamB, PhoA, MalE and pelB were synthesized by Sprin GenBioTech Co. LTD (Nanjing, China). The codon optimization procedure for the two PLD genes were conducted by Sprin GenBioTech Co. LTD (Nanjing, China). We used the primers P1 and P2 to amplify the PLD PMF gene and inserted it into the plasmid pET28a between the NcoI and EcoRI sites, yielding the recombinant plasmid pET28a-PLD PMF. The PLD SR $_{\text {fragment was }}$ amplified using the primer P3 with a NcoI restriction site and primer P4 with an EcoRI restriction site, and was ligated into pET-28a vector, yielding the plasmid pET28a-PLD ${ }_{S R}$. 
Table 3. Primers used in this study.

\begin{tabular}{|c|c|c|}
\hline Name & Primers & Sequences $\left(5^{\prime}-3^{\prime}\right)$ \\
\hline P1 & NcoI-PLD ${ }_{\text {PMF }}-\mathrm{F}$ & CATGCCATGGCAGCTGACTCTGCTACCCCG \\
\hline P2 & EcoRI-PLD ${ }_{\text {PMF }}-R$ & CCGGAATTCTCAGGCGTTGCAGATCCC \\
\hline P3 & NcoI-PLD $_{S R}-\mathrm{F}$ & CATGCCATGGGTGCGGAGGTGTGGTCGTAC \\
\hline $\mathrm{P} 4$ & EcoRI-PLD ${ }_{S R}-R$ & CCGGAATTCTCAGGCCTGGCAGAGG \\
\hline P5 & NdeI-Nat-PLD * & GGAATTCCATATGCTACATGGGTCACACCT \\
\hline P6 & Xhol-Nat-PLD* & CTCGAGCGGAGCGTTGCAGATACCAC \\
\hline P7 & NcoI-OmpA-Nat-PLD * & CCATGGGCTACATGGGTCACA \\
\hline P8 & XhoI-OmpA-Nat-PLD * & CTCGAGCGGAGCGTTGCAGATACCAC \\
\hline P9 & NcoI-OmpA-PLD * & CATGCCATGGCAGCTGACTCTGCTACCCCG \\
\hline P10 & XhoI-OmpA-PLD * & CTCGAGCGGAGCGTTGCAGATACCAC \\
\hline P11 & LamB-F & GGAATTCCATATGATTACTCTGCGCAAACTTCCTCTGGCGGTTGCCGTCGCAGCGGGCGTAATGTCTGCTCAGGCAATGGCTCCATGGGCTACATGGGTCACA \\
\hline P12 & MalE-F & GGAATTCCATATGAAAATAAAAACAGGTGCACGCATCCTCGCATTATCCGCATTAACGACGATGATGTTTTCCGCCTCGGCTCTCGCCCCATGGGCTACATGGGTCACA \\
\hline P13 & OmpC-F & GGAATTCCATATGAAAGTTAAAGTACTGTCCCTCCTGGTCCCAGCTCTGCTGGTAGCAGGCGCAGCAAACGCTCCATGGGCTACATGGGTCACA \\
\hline P14 & OmpF-F & GGAATTCCATATGAAGCGCAATATTCTGGCAGTGATCGTCCCTGCTCTGTTAGTAGCAGGTACTGCAAACGCTCCATGGGCTACATGGGTCACA \\
\hline P15 & OmpT-F & GGAATTCCATATGCGGGCGAAACTTCTGGGAATAGTCCTGACAACCCCTATTGCGATCAGCTCTTTTGCTCCATGGGCTACATGGGTCACA \\
\hline P16 & PhoA-F & GGAATTCCATATGAAACAAAGCACTATTGCACTGGCACTCTTACCGTTACTGTTTACCCCTGTGACAAAAGCCCCATGGGCTACATGGGTCACA \\
\hline P17 & PelB-F & GGAATTCCATATGAAATACCTGCTGCCGACCGCTGCTGCTGGTCTGCTGCTCCTCGCTGCCCAGCCGGCGATGGCCATGGGCTACATGGGTCACA \\
\hline P18 & General reverse primer & CTCGAGCG+GAGCGTTGCAGATACCAC \\
\hline
\end{tabular}


For secretory expression of PLD, PLD ${ }_{\mathrm{PMF}}$ was cloned into plasmid $\mathrm{pET} 22 \mathrm{~b}$ together with different signal peptides. Primers P5/P6 were used for PCR amplification of the PLD PMF gene containing the native signal peptide (Nat), while the primers P7/P8 were used to obtain the fragment OmpA-Nat-PLD *, and primers P9/P10 were used to obtain the fragment OmpA-PLD *. These three fragments were inserted into NcoI/XhoI sites of plasmid pET22b to yield the plasmids pET22b-Nat-PLD*, pET22b-OmpA-Nat-PLD *, and pET22b-OmpA-PLD * respectively. To optimize the secretory efficiency, seven other signal peptides OmpC, OmpF, OmpT, LamB, PhoA, MalE and PelB were amplified using appropriate primers listed in Table 3 to replace OmpA of plasmid pET22b-OmpA-Nat-PLD *.

\subsection{Protein Expression and Cell Fractionation}

The engineered E. coli was cultivated in $100 \mathrm{~mL}$ LB medium with $0.1 \mathrm{~mm}$ of appropriate antibiotics at $37^{\circ} \mathrm{C}$ on a rotatory shaker $(200 \mathrm{rpm})$. When the cell-culture density at $600 \mathrm{~nm}\left(\mathrm{OD}_{600}\right)$ reached 0.6 , $0.5 \mathrm{~mm} \beta$-d-1-thiogalactopyranoside (IPTG) was added into the culture. Then the cells were incubated at $28{ }^{\circ} \mathrm{C}$ for $12 \mathrm{~h}$. As shown in Figure $7 \mathrm{a}$, cells were harvested by centrifugation at $8000 \mathrm{rpm}$ for $10 \mathrm{~min}$. The supernatant was used as the extracellular fraction to test the activity of extracellular PLD secreted into the culture medium. The collected cells were washed twice with deionized water and was resuspended in water to an $\mathrm{OD}_{600 \mathrm{~nm}}$ of 20 for the preparation of intracellular fraction. Intracellular fraction was prepared on ice by ultrasonication: $20 \mathrm{~min}$ pulsing $(0.3 \mathrm{~ms}, 0.2 \mathrm{~ms}$ pause) at $40 \%$ input power and insoluble fraction of the lysate was removed by centrifugation $\left(8000 \mathrm{rpm}\right.$ for $30 \mathrm{~min}$ at $\left.4{ }^{\circ} \mathrm{C}\right)$. The intracellular fraction was used to evaluate the intracellular PLD activity.

(a)

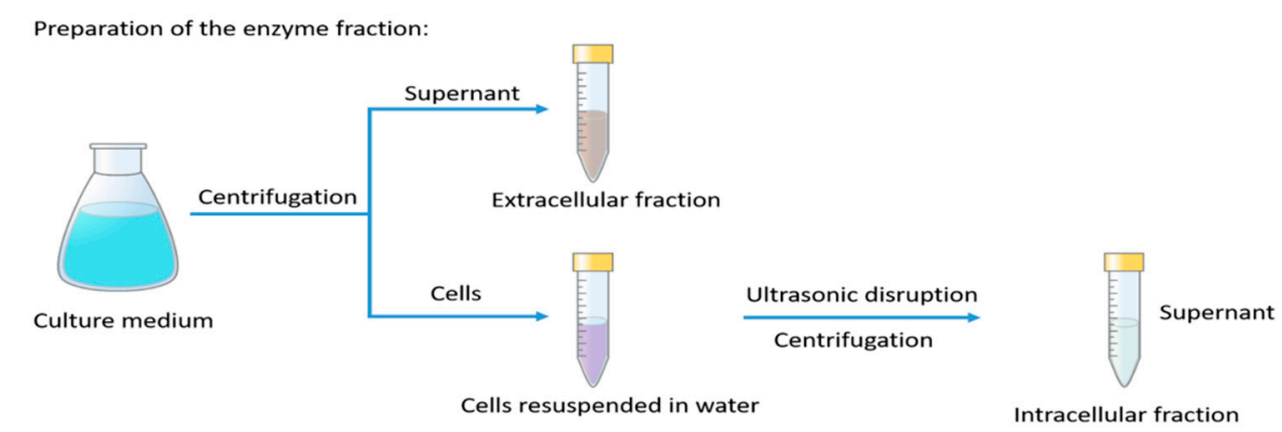

(b)

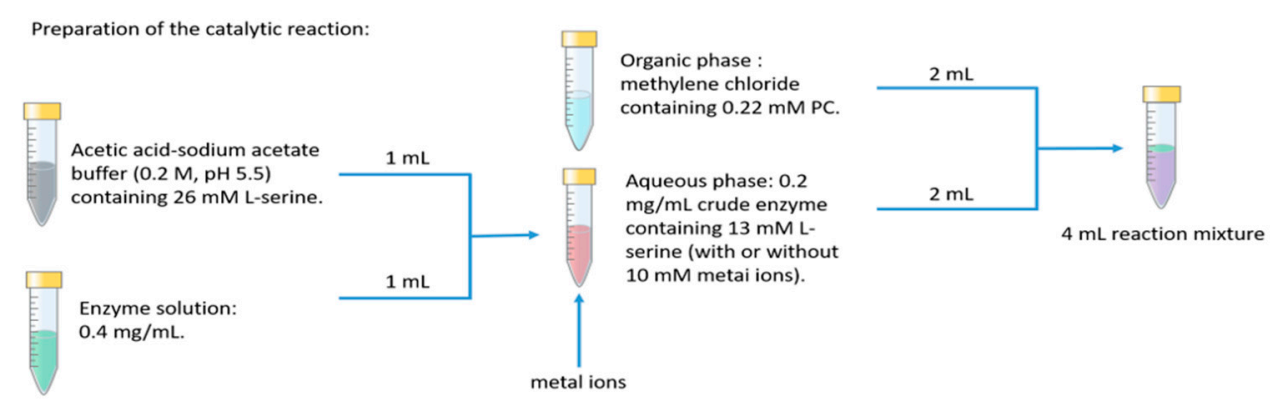

Figure 7. Flow charts of crude enzyme preparation and catalytic reaction. (a) Preparation of the crude enzyme. (b) Preparation of the catalytic reaction.

\subsection{Enzyme Assay}

The transphosphatidylation activity of PLD was measured according to the production of PS. One unit (U) was defined as $1 \mu \mathrm{mol}$ PS produced per $1 \mathrm{~min}$. To determine the PLD activity, a catalytic reaction was carried out in a two-phase system (Figure $7 \mathrm{~b}$ ). The aqueous phase with or without $10 \mathrm{~mm}$ 
metal ions $\left(\mathrm{Co}^{2+}, \mathrm{Ni}^{2+}, \mathrm{Zn}^{2+}, \mathrm{Cu}^{2+}, \mathrm{Ca}^{2+}, \mathrm{K}^{+}, \mathrm{Fe}^{2+}, \mathrm{Mg}^{2+}, \mathrm{Mn}^{2+}\right)$ containing $13 \mathrm{~mm}$ L-serine consists of $1 \mathrm{~mL}$ enzyme solution (intracellular fraction or extracellular fraction containing $0.4 \mathrm{mg}$ crude enzymes) and $1 \mathrm{~mL}$ acetic acid-sodium acetate buffer $(0.2 \mathrm{M}, \mathrm{pH}$ 5.5). The organic phase was $2 \mathrm{~mL}$ methylene chloride containing $0.22 \mathrm{~mm}$ PC. The reaction mixture was incubated in a $200 \mathrm{rpm}$ shaker at $30^{\circ} \mathrm{C}$ for $4 \mathrm{~h}$. Then, the reaction mixture was centrifuged $\left(8000 \mathrm{rpm}, 4^{\circ} \mathrm{C}, 10 \mathrm{~min}\right)$ and the organic phase was retained. After that, a $100 \mu \mathrm{L}$ organic sample was taken from the methylene chloride solution and diluted 10 times with a mixture containing chloroform and methanol with a volume ratio of 2:1. Then, the diluted sample was determined by HPLC.

\subsection{Analytical Methods}

The samples were analyzed by high-performance liquid chromatography (HPLC) (Agilent 1260, Palo Alto, California, USA) equipped with a CHROMA-CHEM evaporative light scattering detector (ELSD). The separation of PS and PC was performed on a ZORBAX Rx-SIL silica gel column $(5 \mu \mathrm{m}$, $250 \mathrm{~mm} \times 4.6 \mathrm{~mm}$, Agilent). Mobile phase A contained $85 \%$ methanol, $14.5 \%$ water, $0.45 \%$ acetic acid and $0.05 \%$ trimethylamine; mobile phase B contained $20 \%$ n-hexane, $48 \%$ isopropanol and $32 \%$ mobile phase A. The flow rate was $1.0 \mathrm{~mL} \mathrm{~min}{ }^{-1}$. The elution conditions were as follows: initially mobile phase was $2 \% \mathrm{~A}$ and $98 \% \mathrm{~B} ; 10 \% \mathrm{~A}$ and $90 \% \mathrm{~B}$ elute for $5 \mathrm{~min} ; 30 \% \mathrm{~A}$ and $70 \% \mathrm{~B}$ elute for $4 \mathrm{~min} ; 10 \% \mathrm{~A}$ and $90 \%$ B elute for $5 \mathrm{~min}$; finally, $2 \% \mathrm{~A}$ and $98 \% \mathrm{~B}$ elute for $3 \mathrm{~min}$. The column temperature, nebulizing temperature and evaporating temperature were controlled at $38{ }^{\circ} \mathrm{C}, 72{ }^{\circ} \mathrm{C}$ and $72{ }^{\circ} \mathrm{C}$, respectively, and nitrogen was used as the nebulizing gas. The nitrogen gas flow rate was 2.0 SLPM (standard liters per minute). Each phospholipid was determined from the retention time using calibration solutions of corresponding phospholipids, and the concentrations of the phospholipids in the samples were calculated from the peak areas by integration.

\section{Conclusions}

In this study we cloned and expressed the PLD from Streptomyces PMF in E. coli; the strain BL21(DE3)/pET28a-PLD ${ }_{\text {PMF }}$ only exhibited intracellular PLD activity. In order to release the negative effects caused by the toxicity of PLD we constructed the strain BL21 (DE3)/pET22b-PLDPMF to secrete the PLD into the culture medium and the supernatant of the culture exhibited PLD activity producing $1.23 \mathrm{~g} / \mathrm{L}$ PS in $8 \mathrm{~h}$. Then, we investigated the effects of signal peptides and adding surfactants on the secretory production of PLD. Strain BL21(DE3)/PelB-Nat-PLD * showed the highest extracellular PLD activity. With the addition of $3 \mathrm{~g} / \mathrm{L}$ Span60, the extracellular fraction was used for catalytic reaction, and the concentration of PS reached $4.51 \mathrm{~g} / \mathrm{L}, 3.67$-fold higher than strain BL21 (DE3)/pET22b-PLD PMF. After optimizing the induction conditions and catalytic situations, the recombinant PLD of the strain BL21 (DE3)/PelB-Nat-PLD * produced $30.2 \mathrm{~g} / \mathrm{L}$ PS in $24 \mathrm{~h}$. With the advantages of simple operations, low cost of recycling the PLD and high activity of the enzyme, our work makes large-scale production of PLD and PS feasible.

Author Contributions: Conceptualization, X.W., K.C. and P.O.; data curation, J.W., S.X. and X.W.; formal analysis, S.X.; funding acquisition, X.W. and P.O.; investigation, J.W. and Y.P.; methodology, S.X. and Y.P.; project administration, K.C.; writing —original draft, J.W.; writing—review and editing, J.W. and X.W. All authors have read and agreed to the published version of the manuscript.

Funding: This research was funded by the National Key Research and Development Program of China (Grant No. 2018YFA0901500), National Natural Science Foundation of China (Grant No. 21606127, Grant No. 21706126) and, Jiangsu synergetic innovation center for advanced bio-manufacture (Grant No. XTB1802, Grant No. XTE1844).

Conflicts of Interest: The authors declare no conflict of interest. 


\section{References}

1. Nakazawa, Y.; Sagane, Y.; Sakurai, S.-I.; Uchino, M.; Sato, H.; Toeda, K.; Takano, K. Large-Scale Production of Phospholipase D from Streptomyces racemochromogenes and Its Application to Soybean Lecithin Modification. Appl. Biochem. Biotechnol. 2011, 165, 1494-1506. [CrossRef] [PubMed]

2. Doig, S.D.; Diks, R.M.M. Toolbox for exchanging constituent fatty acids in lecithins. Eur. J. Lipid Sci. Technol. 2003, 105, 359-367. [CrossRef]

3. Altshuller, Y.M. Human ADP-ribosylation Factor-activated Phosphatidylcholine-specific Phospholipase D Defines a New and Highly Conserved Gene Family. J. Boil. Chem. 1995, 270, 29640-29643. [CrossRef] [PubMed]

4. Khatoon, H.; Mansfeld, J.; Schierhorn, A.; Ulbrich-Hofmann, R. Purification, sequencing and characterization of phospholipase D from Indian mustard seeds. Phytochemistry 2015, 117, 65-75. [CrossRef]

5. Frohman, M.A. The phospholipase D superfamily as therapeutic targets. Trends Pharmacol. Sci. 2015, 36, 137-144. [CrossRef] [PubMed]

6. Hagishita, T.; Nishikawa, M.; Hatanaka, T. Isolation of phospholipase d producing microorganisms with high transphosphatidylation activity. Biotechnol. Lett. 2000, 22, 1587-1590. [CrossRef]

7. Ramrakhiani, L.; Chand, S. Recent Progress on Phospholipases: Different Sources, Assay Methods, Industrial Potential and Pathogenicity. Appl. Biochem. Biotechnol. 2011, 164, 991-1022. [CrossRef]

8. Carrea, G.; D'Arrigo, P.; Piergianni, V.; Roncaglio, S.; Secundo, F.; Servi, S. Purification and properties of two phospholipases D from Streptomyces sp. Biochim. Biophys. Acta (BBA) Lipids Lipid Metab. 1995, 1255, 273-279. [CrossRef]

9. Ogino, C.; Kanemasu, M.; Fukumoto, M.; Kubo, T.; Yoshino, T.; Kondo, A.; Fukuda, H.; Shimizu, N. Continuous production of phospholipase D using immobilized recombinant Streptomyces lividans. Enzym. Microb. Technol. 2007, 41, 156-161. [CrossRef]

10. Chen, S.; Xu, L.; Li, Y.; Hao, N.; Yan, M. Bioconversion of phosphatidylserine by phospholipase $\mathrm{D}$ from Streptomyces racemochromogenes in a microaqueous water-immiscible organic solvent. Biosci. Biotechnol. Biochem. 2013, 77, 130388. [CrossRef]

11. Lee, J.-S.; Bat-Ochir, M.; Demirev, A.V.; Nam, D.H. Molecular cloning of the phospholipase D gene from Streptomyces sp. YU100 and its expression in Escherichia coli. J. Microbiol. 2009, 47, 116-122. [CrossRef] [PubMed]

12. Zhou, W.-B.; Gong, J.-S.; Hou, H.-J.; Li, H.; Lu, Z.-M.; Xu, H.-Y.; Xu, Z.-H.; Shi, J.-S. Mining of a phospholipase $\mathrm{D}$ and its application in enzymatic preparation of phosphatidylserine. Bioengineered 2018, 9, 80-89. [CrossRef] [PubMed]

13. Choojit, S.; Bornscheuer, U.T.; Upaichit, A.; H-Kittikun, A. Efficient phosphatidylserine synthesis by a phospholipase D fromStreptomycessp. SC734 isolated from soil-contaminated palm oil. Eur. J. Lipid Sci. Technol. 2016, 118, 803-813. [CrossRef]

14. Ogino, C.; Kanemasu, M.; Hayashi, Y.; Kondo, A.; Shimizu, N.; Tokuyama, S.; Tahara, Y.; Kuroda, S.; Tanizawa, K.; Fukuda, H. Over-expression system for secretory phospholipase D by Streptomyces lividans. Appl. Microbiol. Biotechnol. 2004, 64, 823-828. [CrossRef] [PubMed]

15. Liu, Y.; Zhang, T.; Qiao, J.; Liu, X.; Bo, J.; Wang, J.; Lu, F. High-Yield Phosphatidylserine Production via Yeast Surface Display of Phospholipase D from Streptomyces chromofuscus on Pichia pastoris. J. Agric. Food Chem. 2014, 62, 5354-5360. [CrossRef]

16. Zambonelli, C. Cloning and expression in Escherichia coli of the gene encoding Streptomyces PMF PLD, a phospholipase D with high transphosphatidylation activity. Enzym. Microb. Technol. 2003, 33, 676-688. [CrossRef]

17. Xiong, W.; Zeng, X.; Ho, S.-H.; Ling, X.; Shen, L.; Yao, C.; Lu, Y. Strategies for achieving high-level and stable production of toxic Streptomyces phospholipase D in Escherichia coli. J. Chem. Technol. Biotechnol. 2019, 94, 1220-1229. [CrossRef]

18. Hikita, C.; Mizushima, S. Effects of total hydrophobicity and length of the hydrophobic domain of a signal peptide on in vitro translocation efficiency. J. Boil. Chem. 1992, 267, 4882-4888.

19. Li, Z.; Li, B.; Liu, Z.-G.; Wang, M.; Gu, Z.-B.; Du, G.-C.; Wu, J.; Chen, J. Calcium Leads to Further Increase in Glycine-Enhanced Extracellular Secretion of Recombinant $\alpha$-Cyclodextrin Glycosyltransferase inEscherichia coli. J. Agric. Food Chem. 2009, 57, 6231-6237. [CrossRef] 
20. Shin, H.-D.; Chen, R. Extracellular recombinant protein production from anEscherichia coli lppdeletion mutant. Biotechnol. Bioeng. 2008, 101, 1288-1296. [CrossRef]

21. Su, L.; Chen, S.; Yi, L.; Woodard, R.W.; Chen, J.; Wu, J. Extracellular overexpression of recombinant Thermobifida fusca cutinase by alpha-hemolysin secretion system in E. coli BL21(DE3). Microb. Cell Factories 2012, 11, 8. [CrossRef] [PubMed]

22. Selvy, P.E.; Lavieri, R.R.; Lindsley, C.W.; Brown, H.A. Phospholipase D: Enzymology, Functionality, and Chemical Modulation. Chem. Rev. 2011, 111, 6064-6119. [CrossRef]

23. Cerminati, S.; Paoletti, L.; Aguirre, A.; Peirú, S.; Menzella, H.G.; Castelli, M.E. Industrial uses of phospholipases: Current state and future applications. Appl. Microbiol. Biotechnol. 2019, 103, 2571-2582. [CrossRef] [PubMed]

24. Jeucken, A.; Helms, J.B.; Brouwers, J.F. Cardiolipin synthases of Escherichia coli have phospholipid class specific phospholipase D activity dependent on endogenous and foreign phospholipids. Biochim. Biophys. Acta (BBA) Mol. Cell Boil. Lipids 2018, 1863, 1345-1353. [CrossRef]

25. Mayr, J.A.; Kohlwein, S.D.; Paltauf, F. Identification of a novel, $\mathrm{Ca}^{2+}$-dependent phospholipase D with preference for phosphatidylserine and phosphatidylethanolamine inSaccharomyces cerevisiae. FEBS Lett. 1996, 393, 236-240. [CrossRef]

26. Huang, T.; Lv, X.; Li, J.; Shin, H.-d.; Du, G.; Liu, L. Combinatorial Fine-Tuning of Phospholipase D Expression by Bacillus subtilis WB600 for the Production of Phosphatidylserine. J. Microbiol. Biotechnol. 2018, 28, 2046-2056. [CrossRef]

27. Makino, T.; Skretas, G.; Georgiou, G. Strain engineering for improved expression of recombinant proteins in bacteria. Microb. Cell Factories 2011, 10, 32. [CrossRef]

28. Pechsrichuang, P.; Songsiriritthigul, C.; Haltrich, D.; Roytrakul, S.; Namvijtr, P.; Bonaparte, N.; Yamabhai, M. OmpA signal peptide leads to heterogenous secretion of B. subtilis chitosanase enzyme from E. coli expression system. SpringerPlus 2016, 5, 1200. [CrossRef]

29. Valent, Q.A.; Scotti, P.A.; High, S.; De Gier, J.L.; Von Heijne, G.; Lentzen, G.; Wintermeyer, W.; Oudega, B.; Luirink, J. The Escherichia coli SRP and SecB targeting pathways converge at the translocon. EMBO J. 1998, 17, 2504-2512. [CrossRef]

30. Choi, J.H.; Lee, S.Y. Secretory and extracellular production of recombinant proteins using Escherichia coli. Appl. Microbiol. Biotechnol. 2004, 64, 625-635. [CrossRef]

31. Chen, R. Permeability issues in whole-cell bioprocesses and cellular membrane engineering. Appl. Microbiol. Biotechnol. 2007, 74, 730-738. [CrossRef] [PubMed]

32. Simkhada, J.R.; Lee, H.J.; Jang, S.Y.; Kim, J.H.; Lee, H.C.; Sohng, J.K.; Yoo, J.C. A novel low molecular weight phospholipase D from Streptomyces sp. CS684. Bioresour. Technol. 2009, 100, 1388-1393. [CrossRef] [PubMed]

33. Zambonelli, C.; Roberts, M.F. An Iron-dependent Bacterial Phospholipase D Reminiscent of Purple Acid Phosphatases. J. Boil. Chem. 2003, 278, 13706-13711. [CrossRef] [PubMed]

34. Duan, Z.-Q.; Hu, F. Efficient synthesis of phosphatidylserine in 2-methyltetrahydrofuran. J. Biotechnol. 2013, 163, 45-49. [CrossRef] [PubMed]

35. Li, B.; Lu, F.-P.; Tian, L.; Li, Y.; Du, L. Cloning and expression of phospholipase D genepld fromStreptomyces chromofuscus. Ann. Microbiol. 2008, 58, 227-231. [CrossRef]

(C) 2020 by the authors. Licensee MDPI, Basel, Switzerland. This article is an open access article distributed under the terms and conditions of the Creative Commons Attribution (CC BY) license (http://creativecommons.org/licenses/by/4.0/). 